\section{Commentary: Is two ever better than one in pediatric ventricular assist device support? The controversy continues}

Kyle W. Riggs, MD, David L. S. Morales, MD, and Farhan Zafar, MD

Hernandez and colleagues ${ }^{1}$ have tried to resuscitate the idea that biventricular assist device (BiVAD) support in pediatric heart failure has similar outcomes as left ventricular assist device (LVAD) support by performing a propensitymatched analysis of the Pedimacs database. It has always been clear that patients undergoing BiVAD placement have been objectively more ill than children receiving an LVAD. ${ }^{2}$ However, like most analyses looking at BiVADs, there is always a large assumption that the fact a patient received a BiVAD means the person needed a BiVAD, which many would speculate is not true. In their analysis, they meticulously matched 9 common risk factors for BiVAD and LVAD recipients, including age, mechanical ventilation, Pedimacs profile, and cardiac diagnosis. This resulted in 40 of $63 \mathrm{BiVAD}$ recipients being matched to 80 of 313 LVAD recipients with a finding of similar postimplant survival to 6 months and higher bleeding events being the only increased mortality identified in BiVAD recipients. However, even if this is not significantly increased (probably a type II error), patients on BiVAD support took longer to recover with worse end-organ function demonstrated by elevated bilirubin (LVAD $21 \%$ vs BiVAD $37 \%, P=.11$ ), patients requiring mechanical ventilation (LVAD $42 \%$ vs BiVAD $63 \%, P=.06$ ), and patients on dialysis (LVAD $6.6 \%$ vs BiVAD $13.3 \%, P=.22$ ).

\footnotetext{
From the Department of Cardiothoracic Surgery, Cincinnati Children's Hospital Medical Center, Cincinnati, Ohio.

Disclosures: Dr Morales is a consultant, instructor, and advisor to Berlin Heart; a proctor, consultant, instructor, and national principle investigator for the 50/50 trial for SynCardia; and a consultant within the HeartWare Division of Medtronic and the Thoratec Division of Abbott. Dr Zafar is a consultant for SynCardia. Dr Riggs has nothing to disclose with regard to commercial support.

Received for publication Jan 6, 2020; revisions received Jan 6, 2020; accepted for publication Jan 6, 2020; available ahead of print Jan 31, 2020.

Address for reprints: Kyle W. Riggs, MD, 3333 Burnet Ave, Cincinnati, OH 45229 (E-mail: kcriggs00@gmail.com).

J Thorac Cardiovasc Surg 2020;160:1309-10

$0022-5223 / \$ 36.00$

Copyright (c) 2020 by The American Association for Thoracic Surgery

https://doi.org/10.1016/j.jtcvs.2020.01.026
}

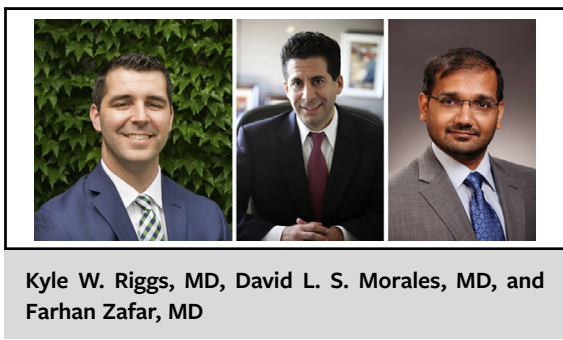

\begin{abstract}
CENTRAL MESSAGE
Although data may suggest pediatric patients with BiVAD support can have similar survival as patients supported with an LVAD, delayed BiVAD placement and using BiVAD support in those who only required LVADs obscure the true answer.
\end{abstract}

One of the main concerns with this study is that matching only modestly affected the survival of either group. Rather, because of smaller numbers, the confidence intervals became larger and the statistical difference became insignificant, bringing about increased concern for type II error and an incorrect assumption that survival was similar. Prior studies that have found BiVAD support to be a risk factor for mortality have used multivariate analysis that controls for other factors. Although they try to demonstrate equivalent survival between these 2 different groups, the populations they ultimately studied had to be heavily matched on the Pedimacs profile (standardized difference changed from 0.39 to 0.017). Half of all BiVAD support was in patients with critical cardiogenic shock (Pedimacs profile 1), which could be avoided with early implantation and alternate devices. ${ }^{3,4}$ Furthermore, as they point out, the decision to support patients with an LVAD or BiVAD is complex, and a number of patients transition from LVAD to BiVAD, which puts them at an increased risk for mortality. Ultimately, most providers think that those who do well with BiVAD support would have done equally well with just an LVAD. Delineating these intricacies is understandably beyond the capabilities of a retrospective study and is further limited by the relatively low number of pediatric patients supported by ventricular assist devices annually. Unfortunately, this article gives credence to the use of BiVADs in select patient populations without an ability to give indications for BiVAD use over LVAD use. 


\section{References}

1. Hernandez NB, Kirk R, Sutcliffe D, Davies R, Jaquiss R, Gao A, et al. Utilization and outcomes in biventricular assist device support in pediatrics. $J$ Thorac Cardiovasc Surg. 2020;160:1301-8.e2.

2. Zafar F, Jefferies JL, Tjossem CJ, Bryant R III, Jaquiss RD, Wearden PD, et al. Biventricular Berlin Heart EXCOR pediatric use across the United States. Ann Thorac Surg. 2015;99:1328-34.
3. Schibilsky D, Haller C, Lange B, Schibilsky B, Haeberle H, Seizer P, et al. Extracorporeal life support prior to left ventricular assist device implantation leads to improvement of the patients INTERMACS levels and outcome. PLoS One. 2017;12:e174262.

4. Lorts A, Eghtesady P, Mehegan M, Adachi I, Villa C, Davies R, et al. Outcomes of children supported with devices labeled as "temporary" or short term: a report from the pediatric interagency registry for mechanical circulatory support. $J$ Heart Lung Transplant. 2018;37:54-60.
See Article page 1301.

\section{Commentary: To BiVAD or not to BiVAD...that is the question?}

\author{
John C. Dykes, MD, and Katsuhide Maeda, MD, PhD
}

It is well established that pediatric patients with advanced heart failure who receive a biventricular assist device (BIVAD) have worse unadjusted outcomes compared with patients who receive a left ventricular assist device (LVAD) alone. ${ }^{1-3}$ This has led to a long-standing controversy over the optimal role of BIVAD use. Some argue that BIVADS should be strenuously avoided in virtually all cases because the risk is inherent to the right ventricular assist device (VAD) itself, whereas others argue that the poor outcomes are related to patient selection and timing of implant. As with any good controversy, debate thrives largely because of a lack of data to resolve the controversy persuasively.

In this issue of the Journal, Hernandez and colleagues ${ }^{4}$ take an important step forward in filling this data gap in pediatric VAD recipients. Analyzing INTERACS (Interagency Registry for Mechanically Assisted Circulatory Support) data from 363 children implanted with VADs since 2012, the authors show that (1) BIVAD use is on the decline in pediatric patients; (2) patients with LVAD and BIVAD differ substantially in their characteristics at implant, and (3) the difference in adjusted outcomes appears much

From the Departments of Cardiothoracic Surgery \& Pediatrics, Stanford University School of Medicine, Stanford, Calif.

Disclosures: Authors have nothing to disclose with regard to commercial support.

Received for publication Jan 2, 2020; accepted for publication Jan 3, 2020; available ahead of print Jan 11, 2020.

Address for reprints: Katsuhide Maeda, MD, PhD, Department of Cardiothoracic Surgery, Stanford University, 300 Pasteur Dr, Stanford, CA 94305 (E-mail: kmaeda@stanford.edu).

J Thorac Cardiovasc Surg 2020;160:1310-1

$0022-5223 / \$ 36.00$

Copyright (c) 2020 by The American Association for Thoracic Surgery

https://doi.org/10.1016/j.jtcvs.2020.01.003
Check for updates

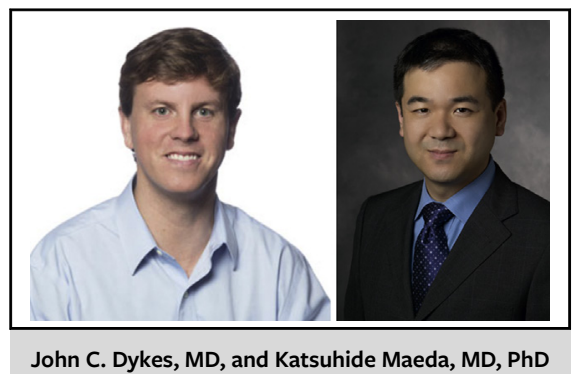

CENTRAL MESSAGE

Poor outcomes traditionally

associated with BiVAD use may

be more related to patient se-

lection and timing of implant

rather than the device strategy.

smaller-and possibly negligible-once the difference in patients characteristics is adjusted for using a propensity score (PS)-matching analysis. ${ }^{4}$ These findings are consistent with a similar study performed in adult patients with VAD that used Cox proportional hazards modeling rather than PS matching to adjust for patient differences. ${ }^{3}$

Use of PS matching to adjust for patient differences has a number of important limitations in this setting that could explain the nonsignificant difference in LVAD versus BIVAD survival. However, a PS-matched approach is still one of the best methods available to answer this important question, given the large number of potential confounders and small sample size available. As the authors note, this also creates problem for generalizability to sicker and healthier patients, where, if adequate controls existed, one might actually observe LVADs to perform better in healthier patients whereas BIVADs perform better in sickest patients. Another limitation is that many of the factors clinicians use to decide to place a right VAD were unavailable for PS 